\title{
SIMULATION OF A PAINT SHOP POWER AND FREE LINE
}

Edward J. Williams

\author{
A-73 Advanced Manufacturing Technology \\ Development \\ Ford Motor Company \\ Redford, Michigan 48239-2698, U.S.A.
}

\author{
Shigeru Sadakane \\ Production Modeling Corporation \\ Three Parklane Boulevard, Suite 910 West \\ Dearborn, Michigan 48126, U.S.A.
}

\begin{abstract}
We describe the application of simulation and statistical analyses to the process improvement of a paint shop within a heavy manufacturing plant. The explicit objectives of this study were the evaluation of throughput relative to loading time, unloading time, and shift patterns, the number of carriers required to maximize this throughput, and the number of operators in the unload zone required to maximize this throughput. Results obtained from this study enabled production engineers and their managers to assure achievement of target throughput and minimize the collective cost of work-in-process plus labor costs for operators in the unload zone.
\end{abstract}

\section{INTRODUCTION}

Material handling, the art and science of moving, storing, protecting, and controlling material between value-adding operations, is one of the most complex, yet economically important, functions within a manufacturing system (Tompkins et al. 1996). Simulation, a powerful technique for analyzing complex systems with interacting components, has a welldeserved and long-term reputation for success in suggesting improvements to manufacturing systems (Clark 1996). The flexibility of simulation permits its application to a wide variety of manufacturing problems, such as capacity planning, machine and personnel scheduling, inventory control, and job routing (Martinich 1997). Specifically, examples of simulation applications to material handling abound in the literature, such as optimization of operating policies for an automated material handling system (Dallari et al. 1996), evaluation of a distribution center tow-line material handling system (Bakst, Hoffner, and Jacoby 1996), configuration of a material delivery system with dolly trains (Jeyabalan and Otto 1992), development of dispatching rules for multiple-vehicle automatic guided vehicle [AGV] systems (Lee 1996), and improvement of a pull-strategy in the order-picking area of a distribution warehouse (Alicke and Arnold 1997).

In the study described here, production managers wished to meet target throughput of a paint shop in which material handling was performed by a power and free line. Specifically, these managers wished to determine the minimal number of carriers and number of operators in the unload zone required to assure achievement of the required throughput. Reducing the number of carriers would reduce capital investment in expensive equipment and also reduce work in process [WIP]; elimination of bottlenecks would improve worker utilization, thus avoiding increased labor costs.

We first present an overview of the pertinent paint shop and material handling operations. Next, we present details of modeling assumptions and data collection; model construction, verification, and validation; and results of experimentation and analysis undertaken with the help of the validated model. The steps within this practical application of simulation adhere rigorously to those advocated by Chance, Robinson, and Fowler (1996) and Ülgen et al. (1994a, 1994b).

\section{OVERVIEW OF THE MATERIAL HANDLING SYSTEM}

The manufacturing operations include hang zones (where parts are hung on carriers for entry to the system), shot blast, a wash area, E-coat, a subsequent Ecoat oven, two paint booths (for application of two different colors), paint ovens, and unhang zones (where parts are removed from carriers for entry to the downstream assembly area). The conceptual relationships among these operations are shown in Figure 1, next page. For example, a visit to the shot blast is optional, and any given part travels through either the wash area or the E-coat operation, but not both. The material handling system supporting transport requirements among these operations comprises fourteen 


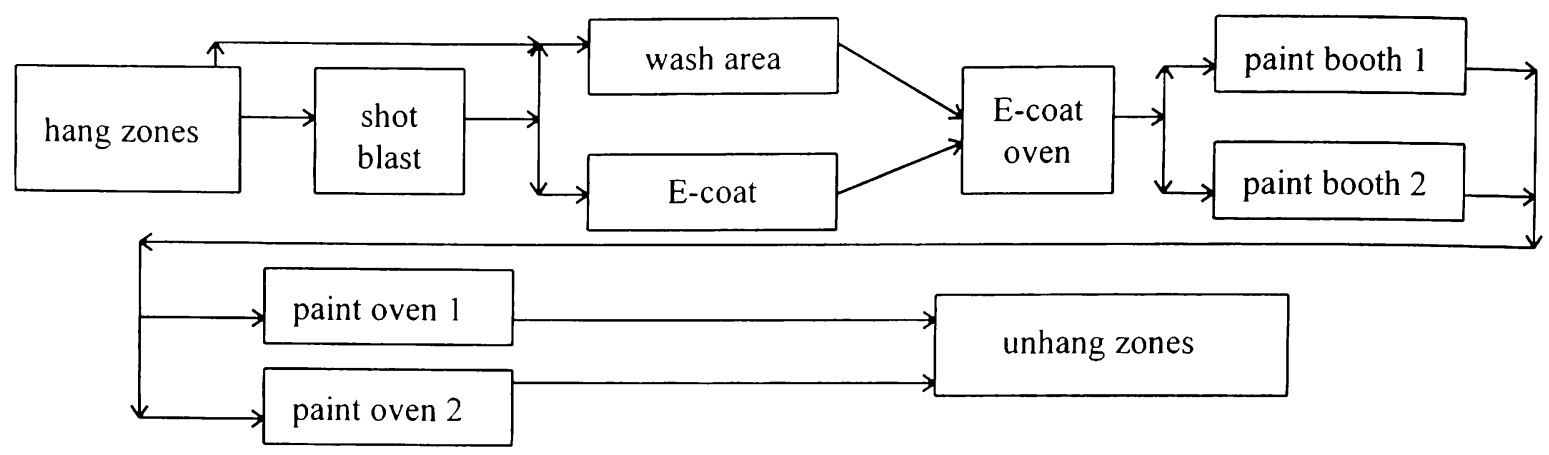

Figure 1: Schematic Layout of Operations

power and free conveyor chains. Power and free conveyors are non-accumulating conveyors (two successive parts on the conveyor must be separated by an integer multiple of a fixed distance) typically used to move workpieces through production processes (Gunal, Sadakane, and Williams 1996). These conveyors use two tracks, one powered and the other unpowered (free). "Dogs" on the power chain mate with ratchets on the free track to engage the carrier trolleys, thus pushing the workpieces aboard these trolleys forward along that track. Routing of workpieces through the system is based on the part type assigned by the carrier; the manufacturing process involves three dozen distinct part types. Table 1 illustrates the differences in manufacturing process flow among four of the highestvolume part types.

Table 1. Operation Sequence for Four Part Types

\begin{tabular}{|c|c|c|c|c|}
\hline Operation & Part A & Part B & Part C & Part D \\
\hline 1 & Blast & Washing & Blast & E-coat \\
\hline 2 & E-coat & Paint A & E-coat & $\begin{array}{l}\text { E-coat } \\
\text { oven }\end{array}$ \\
\hline 3 & $\begin{array}{l}\text { E-coat } \\
\text { oven }\end{array}$ & Oven & $\begin{array}{l}\text { E-coat } \\
\text { oven }\end{array}$ & Paint A \\
\hline 4 & Paint A & Unhang & Paint B & Oven \\
\hline 5 & Oven & & Oven & Unhang \\
\hline 6 & Unhang & & Unhang & \\
\hline
\end{tabular}

Additionally, there are two distinct sizes of carriers; any given part must be transported by one or the other. Small carriers outnumber large by approximately $5: 1$. There are complex relationships among the various operating stations and the fourteen conveyors. Also, a variety of shift patterns is in effect. Some operations run two shifts each weekday; others, three shifts each weekday; still others, either two or three shifts seven days a week. These diverse shift patterns imply high complexity of operational planning and opportunities for computer analyses to yield payroll cost savings while meeting production quotas and dates with minimal disruption (Studebaker 1997).

\section{MODEL ASSUMPTIONS AND DATA COLLECTION}

\subsection{Modeling Assumptions}

The plant engineering team and the model builders agreed, during extensive meetings prior to model build, upon the following assumptions:

- the standard $81 / 2$-hour shift pattern includes two tenminute breaks, one on each side of a 35-minute lunch, and a five-minute end-of-shift cleanup period, for a total working time of $7 \frac{1}{2}$ hours

- workpieces are loaded at the hang zones at a rate specified by carriers/shift $=$ number of required carriers per day / number of available hours per day

- no downtime is modeled

- conveyor details (e.g., length, speed, and dog spacing) are as specified in literature from the facilities-and-tooling vendor supplying the conveyors

- clearances are:

- for a turn, 16 feet (i.e., a carrier must stay at a stop until 16 feet of conveyor downstream from the turn are vacant)

- for a merge, 19 feet (i.e., carriers must stay at the stops until 19 feet of conveyor downstream from the stops are vacant)

- for a split, 28 feet (i.e., a carrier must stay at the stop until 28 feet of conveyor downstream on the chosen path are vacant).

Preparation of a detailed list of assumptions, agreed upon by representatives of the client engineers and the model building team, represents avoidance of a 
significant pitfall on the road to simulation project success (Harrell and Tumay 1995).

\subsection{Data Collection}

In addition to the data already mentioned above (the system layout and conveyor interfaces, details of conveyor geometry and operation, and the structure of the standard shift pattern, large volumes of other data were collected. These data included the input rate broken down by part types, the size of carrier needed by each part type, the sequence of operations each part type must visit, processing times for each part type at each operation, load and unload times, precedence rules for carriers in "competition" at conveyor crossover or merge points, and the structures of non-standard shifts used at some of the operations. Since many of these data details were highly volatile, the data were loaded into files and spreadsheets for easy checking, confirmation, and possible subsequent change. Also, the plant had an incentive labor policy which needed to be factored into various manual-operation cycle times. As often happens, particularly in simulation projects, such as this one, with tight time constraints, data collection became an ongoing process partly concurrent with the building of initial models (Harrell et al. 1995), and also with verification and validation (Lilegdon et al. 1996). The success of these extensive data-gathering efforts rested upon use of available historical data, coordinated time studies, numerous interviews with production personnel, and simulation modelers who were "comfortable in steel-toed shoes" (Black 1996).

\section{MODEL BUILD, VERIFICATION, AND VALIDATION}

After discussions with the customer, the modeling team decided to build the model using the WITNESS ${ }^{\text {TM }}$ simulation software package. This package contains numerous constructs for modeling significant components of the actual system, such as conveyors, machines, and operators. Additionally, this software supports the concurrent creation of an animation along with the model itself (Thompson 1996). However, in the context of WITNESS ${ }^{\mathrm{TM}}$ modeling, representing the exact details of the power and free line and of the various shift patterns required considerable effort.

The modeling analysts used various techniques to verify the model (confirm that it operated as they intended). These techniques included structured walkthroughs, extensive use of simulation traces, and lengthy, careful observation of the animation.

Likewise, the analysts and the client engineers and managers worked together to validate the model (confirm that it accurately represented the actual manufacturing system). Validation techniques included Turing tests, degenerate tests, fixed value tests, and comparison with actual historical data available from the operation of the actual system (Sargent 1996). For example, an early Turing test failed because the model showed no backlog between E-coat and the paint booths, whereas the client engineers were acutely aware of a severe "real-life" backlog there whenever the paint booths were off-shift. Correction of this mistake required addition of properly specified shift schedules for these operations to the model. Similarly, degenerate and fixed value tests exposed a misunderstanding concerning the cycle time at the hang zones. The analysts then explained to the engineers that this model needed the actual "hang time" as that cycle time, not the considerably longer but largely concurrent upstream machine cycle time originally quoted. All these techniques were applied to the base model of the existing system, therefore achieving its credibility among the client engineers and managers, before undertaking any modifications to the base model. These modifications were then chosen to represent system configuration alternatives deemed worthy of consideration for meeting target throughput at reduced cost.

\section{MODEL RESULTS AND ANALYSES}

Analyses performed with the base model indicated that the system as designed could not meet the target throughput. Detailed analyses showed that problem areas were some of the load patterns and routing rules associated with the shift patterns of the E-coat, paint, blast, load and unhang zones. Some parts were scheduled to be loaded too often for an operator in one shift. This issue was resolved through the availability analyses of operators and empty carriers. In the initial stage, hang spurs in the loading area were poorly utilized; thus many empty carriers passed all hang spurs and went to the return line which recirculated the empty carriers to the load zone. Even though no empty carriers were allowed to leave the load zone via the return line, such a carrier required a disproportionately long time to return to the first hang spur. These delays caused long idle times for, and hence low utilization of, the hang spur operators. The delay problem was solved by utilizing the spurs. In some areas, the capacities of spurs were increased.; in others, multiple spurs were specified to share empty carriers. After these modifications, fewer empty carriers passed all hang spurs en route to recirculation, and the idle times of the operators decreased. 
Shift patterns of the E-coat, paint, and blast zones represented another problem. The E-coat zone and the blast zone are both relatively close to the hang zones. Therefore, when either the E-coat or the blast zone is closed by virtue of being off-shift, parts which need to go to either zone will be blocked. If there is too little accumulation space between these zones and the hang zones, the blockage will affect the hang zones. This simulation study showed these blockages to affect the hang zones more rapidly than expected. To postpone the development of blockage within the hang zones, the modeling team recommended using off-shift load spurs as buffer spurs and increasing the interarrival time from the empty-carrier-return line into the hang zones. Many load stations are unavailable when the E-coat and blast zones are off-shift. Therefore, increasing this interarrival time, the number of empty carriers passing all active load stations is reduced. Overall system performance proved highly sensitive to this interarrivaltime parameter: too short an interarrival time failed to reduce the blockage, whereas too long an interarrival time failed to keep the active hang zones busy by supplying enough carriers.

Another part of the problem was the shift pattern of the unhang zones. There were seven unhang stations in the system. During second shift, five operators were responsible for covering all seven stations; during the first shift, one operator was responsible for covering six stations. Although many hang stations were unavailable during first shift, the first shift of the unhang zones was found to be busier because several hours were required for carriers to travel from the hang zones to the unhang zones and the hang zones were scheduled to operate during the third shift. The modeling team suggested assigning at least two operators for the unhang zones during the first shift. Simulation results highlighted a sharp difference between using one operator and using two operators during the first shift. With only one operator assigned to the unhang zones during the first shift, an average of 100 empty carriers would be available to the hang zones at the beginning of the second shift. However, with a second operator assigned to first-shift duty in the unhang zones, an average of 142 empty carriers would be available at the beginning of the next (second) shift. This difference was very significant to the client because the second shift, relative to the overall system, is the busiest of the three. Therefore, the $40 \%+$ increase in empty carriers in readiness for that shift amply compensated for the labor costs of the second operator, hence decreasing aggregate operating costs. Significant examples of these simulation-based reductions in variability of throughput are shown in Table 2, top of the next column.
Table 2: Throughput Variability for 1000 Days' Production

$\begin{array}{cccc}\begin{array}{c}\text { Number of } \\ \text { 1st Shift }\end{array} & \begin{array}{c}\text { Carriers } \\ \text { Scheduled } \\ \text { Operators }\end{array} & \begin{array}{c}\text { Minimum } \\ \text { Daily } \\ \text { Throughput }\end{array} & \begin{array}{c}\text { Maximum } \\ \text { Daily } \\ \text { Throughput }\end{array} \\ 1 & 52 & \text { 32 Part A's } & \text { 59 Part A's } \\ 2 & 52 & \text { 48 Part A's } & \text { 54 Part A's } \\ 1 & 17 & \text { 10 Part B's } & \text { 21 Part B's } \\ 2 & 17 & \text { 14 Part B's } & \text { 19 Part B's }\end{array}$

\section{SUMMARY}

This simulation study proved highly successful in minimizing material-handling equipment expense (by reducing the number of carriers from 252 to 242), reducing the average and maximum work in process, improving utilization of workers and thus avoiding the need for additional hiring, and additionally in increasing the steadiness and hence predictability of output flow. The operational change of sending empty carriers to an inactive spur (sidetrack) when E-coat and the paint booths were both off-shift, rather than sending them to fetch new material from upstream operations immediately, proved especially helpful. This change not only reduced the variability of throughput per unit of time, but also improved efficiency by avoiding starvation of upstream operations. These operations had previously suffered such starvation when carriers attempting to deliver raw material to them were delayed or barricaded by congestion attributable to empty carriers.

Extensions of the model and further analyses are planned to accommodate new models and/or production quota increases of current models, introduction of additional shift patterns, and analyses of potential rearrangement of operation locations on the plant floor. The first two of these are considered nearly certain to occur within the next ten to twelve months.

\section{ACKNOWLEDGMENT}

Dr. Ali Gunal, Systems Consultant, Production Modeling Corporation, and Stuart Gittlitz, Staff Industrial Engineer, Kraft Foods, both provided unusually valuable and explicit suggestions to improve the clarity and organization of this paper. The authors also acknowledge the comments of an anonymous referee.

\section{APPENDIX: TRADEMARK}

WITNESS is a trademark of the Lanner Group. 


\section{REFERENCES}

Alicke, Knut, and Dieter Arnold. 1997. Simulation and optimization of a pull-strategy in the order-picking area of a distribution warehouse. In Proceedings of the $11^{\text {th }}$ European Simulation Multiconference, eds. Ali Riza Kaylan and Axel Lehmann, 369-374.

Bakst, Jay, Joel Hoffner, and Kris Jacoby. 1996. Evaluation of a distribution center tow-line material handling system through simulation modeling. In Proceedings of the 1996 Winter Simulation Conference, eds. John M. Charnes, Douglas J. Morrice, Daniel T. Brunner, and James J. Swain, 1099-1106. IEEE, Piscataway, New Jersey.

Black, Maura. 1996. Detailed modeling of large scale manufacturing. In Simulation Fundamentals \& Applications for the Packaging Industry, Society of Manufacturing Engineers.

Chance, Frank, Jennifer Robinson, and John Fowler. 1996. Supporting manufacturing with simulation: Model design, development, and deployment. In Proceedings of the 1996 Winter Simulation Conference, eds. John M. Charnes, Douglas J. Morrice, Daniel T. Brunner, and James J. Swain, 114121. IEEE, Piscataway, New Jersey.

Clark, Gordon M. 1996. Introduction to manufacturing applications. In Proceedings of the 1996 Winter Simulation Conference, eds. John M. Charnes, Douglas J. Morrice, Daniel T. Brunner, and James J. Swain, 85-92. IEEE, Piscataway, New Jersey.

Dallari, Fabrizio, Gino Marchet, Alessandro Perego, and Remigio Ruggeri. 1996. Simulation of an automated material handling system for order taking. In Proceedings of the $8^{\text {th }}$ European Simulation Symposium, eds. Agostino G. Bruzzone and Eugène J. H. Kerckhoffs, 353-357.

Gunal, Ali K., Shigeru Sadakane, and Edward J. Williams. 1996. Modeling of chain conveyors and their equipment interfaces. In Proceedings of the 1996 Winter Simulation Conference, eds. John M. Charnes, Douglas J. Morrice, Daniel T. Brunner, and James J. Swain, 1107-1114. IEEE, Piscataway, New Jersey.

Harrell, Charles R., Robert E. Bateman, Thomas J. Gogg, and Jack R. A. Mott. 1995. System improvement using simulation, 3rd edition. Orem, Utah: PROMODEL Corporation.

Harrell, Charles, and Kerim Tumay. 1995. Simulation made easy: A manager's guide. Norcross, Georgia: Engineering \& Management Press.

Jeyabalan, Vadivelu, and Norman C. Otto. 1992. Simulation of material delivery systems with dolly trains. In Proceedings of the 1992 Winter Simulation Conference, eds. James J. Swain, David Goldsman,
Robert C. Crain, and James R. Wilson, 916-924. IEEE, Piscataway, New Jersey.

Lee, Jim. 1996. Composite dispatching rules for multiple-vehicle AGV systems. Simulation 66(2):121-130.

Lilegdon, William R., Stuart Gittlitz, Randy D. Moore, and Patrick Reardon. 1996. Simulation works: A panel discussion. In Proceedings of the 1996 Winter Simulation Conference, eds. John M. Charnes, Douglas J. Morrice, Daniel T. Brunner, and James J. Swain, 1337-1340. IEEE, Piscataway, New Jersey.

Martinich, Joseph S. 1997. Production and operations management : An applied modern approach. New York, New York: John Wiley \& Sons, Incorporated.

Sargent, Robert G. 1996. Verifying and validating simulation models. In Proceedings of the 1996 Winter Simulation Conference, eds. John M. Charnes, Douglas J. Morrice, Daniel T. Brunner, and James J. Swain, 55-64. IEEE, Piscataway, New Jersey.

Studebaker, David. 1997. Improving customer satisfaction through advanced scheduling. Industrial Engineering Solutions 29(3):14-17.

Thompson, W. Bruce. 1996. Introduction to the WITNESS visual interactive simulator and OLEII automation. In Proceedings of the 1996 Winter Simulation Conference, eds. John M. Charnes, Douglas J. Morrice, Daniel T. Brunner, and James J. Swain, 547-550. IEEE, Piscataway, New Jersey.

Tompkins, James A., John A. White, Yavuz A. Bozer, Edward H. Frazelle, J. M. A. Tanchoco, and Jaime Trevino. 1996. Facilities planning, 2nd edition. New York, New York: John Wiley \& Sons, Incorporated.

Ülgen, Onur M., John J. Black, Betty Johnsonbaugh, and Roger Klungle. 1994a. Simulation methodology in practice - Part I: Planning for the study. International Journal of Industrial Engineering 1(2):119-128.

Ülgen, Onur M., John J. Black, Betty Johnsonbaugh, and Roger Klungle. 1994b. Simulation methodology in practice - Part II: Selling the results. International Journal of Industrial Engineering 1(2):129-136.

\section{AUTHOR BIOGRAPHIES}

EDWARD J. WILLIAMS holds bachelor's and master's degrees in mathematics (Michigan State University, 1967; University of Wisconsin, 1968). From 1969 to 1971, he did statistical programming and analysis of biomedical data at Walter Reed Army Hospital, Washington, D.C. He joined Ford in 1972, where he works as a computer software analyst supporting statistical and simulation software. Since 1980 , he has taught evening classes at the University of 
Michigan, including both undergraduate and graduate simulation classes using GPSS/H, SLAM II, or SIMAN. $\mathrm{He}$ is a member of the Association for Computing Machinery $[\mathrm{ACM}]$ and its Special Interest Group in Simulation [SIGSIM], the Institute of Electrical and Electronics Engineers [IEEE], the Institute of Industrial Engineers [IIE], the Society for Computer Simulation [SCS], the Society of Manufacturing Engineers [SME], and the American Statistical Association [ASA]. He serves on the editorial board of the International Journal of Industrial Engineering - Applications and Practice.

SHIGERU SADAKANE holds a bachelor's degree in Industrial \& Systems Engineering (University of Michigan - Dearborn, 1994). He is an Applications Engineer at Production Modeling Corporation, and highly familiar with simulation and facilities-layout optimization systems including AutoMod, WITNESS, LayOPT, QUEST, IGRIP, and SIMAN. He is a member of the Institute of Industrial Engineers [IIE] and the Society of Manufacturing Engineers [SME]. 